\title{
Establishment of a Cell Line from an Adenocarcinoma of the Lung Producing Carcinoembryonic Antigen (GEA) and CA19-9
}

\author{
Makoto Miki, Toyoharu Isawa, Takeo Teshima, \\ Yoshiki Anazawa, Asif Mujtaba Mahmud and \\ Toshihiro Nukiwa \\ Department of Respiratory Medicine, Division of Cancer \\ Control, Institute of Development, Aging and Cancer, \\ Tohoku University, Sendai 980-77
}

Miki, M., Isawa, T., Teshima, T., Anazawa, Y., Mahmud, A.M. and Nukiwa, T. Establishment of a Cell Line from an Adenocarcinoma of the Lung Producing Carcinoembryonic Antigen (CEA) and CA19-9. Tohoku J. Exp. Med., 1995, 175 (4), 269-278 — An adenocarcinoma cell line was established from pleural effusion of a 67-year-old woman and designated as TK-SA. The population doubling time of the cells was $100.4 \mathrm{hr}$. Chromosomal analysis revealed the TK-SA to have human aneuploid chromosomes with a near-triploid mode. Ultrastructurally, the TK-SA was compatible with adenocarcinoma. The cell line was highly tumorigenic. 3-(4,5-dimethylthiazol-2-yl)-2, 5-diphenyl tetrazolium bromide dye assay demonstrated resistance of the cell line to Cis-platin (CDDP), Cyclophosphamide (CPM) and Tegafur/Uracil (UFT). High carcinoembryonic antigen (CEA) and CA19-9 levels were similar in patient's serum and conditioned medium. - primary culture; lung cancer; characterization; CEA and CA19-9

Lung cancer constitutes about $20 \%$ of the total annual cancer deaths in Japan and its death rate is increasing rapidly as compared with deaths due to cancer of other organ systems (Tominaga et al. 1989). Establishment of lung cancer cell lines provides many experimental models for studying the histogenesis, diagnosis, therapy and metabolism as well as mechanisms of autonomous growth and metastasis of lung cancer. Especially, a cell line producing a particular substance is useful for elucidation of its metabolism. CEA (carcinoembryonic antigen) (Gold and Freedman 1965a, b) and CA19-9 (Koprowski et al. 1979; Magnani et al. 1982) are the two most well-known substances produced by tumors and are widely used clinically as tumor markers. Few established lung cancer cell lines are reported to produce both CEA and CA19-9 (Masuda et al. 1991). The cell line we

Received June 27, 1994; revision accepted for publication February 10, 1995.

Address for reprints ; Makoto Miki, M.D., Department of Respiratory Medicine, Division of Cancer Control, Institute of Development, Aging and Cancer, Tohoku University, 41 Seiryomachi, Aoba-ku, Sendai 980-77, Japan. 
have established produces these two substances simultaneously.

\section{Materials and Methods}

\section{Clinical data on the TK-SA donor}

Pleural fluid was obtained from a 67-year-old woman with bronchogenic carcinoma. She had been treated with Cis-platin (CDDP), Vindesine (VDS), Adriamycin (ADR), Cyclophosphamide (CPM) and Tegafur/Uracil (UFT) two years before the carcinomatous pleuritis developed. Cytologically the tumor cells in the effusions were diagnosed as adenocarcinoma. The serum CEA and CA19-9 of the patient were elevated at $11 \mathrm{ng} / \mathrm{ml}$ (upper limit of normal, $2.5 \mathrm{ng} / \mathrm{ml}$ ) and $410 \mathrm{U} / \mathrm{ml}$ (upper limit of normal, $37 \mathrm{U} / \mathrm{ml}$ ), respectively, when the pleural effusions were aspirated.

\section{Establishment of the TK-SA cell line}

After centrifugation of the pleural effusions, the cells in pellet form were dispersed in DMEM (Dulbecco's modified Eagle's medium)/Ham's F12 (1:1) (Sigma Chemical Company, St. Louis, MO, USA) supplemented with $10 \%$ fetal bovine serum (FBS), (Gibco BRL, Life Technologies, Inc., Grand Island, NY, USA) $100 \mathrm{U} / \mathrm{ml}$ penicillin and $100 \mu \mathrm{g} / \mathrm{ml}$ streptomycin. $10^{3}$ cells were immediately dispensed into each of the 96 wells of the plate (Sumilon, Sumitomo Bakelite Co., Ltd., Tokyo) and incubated at $37^{\circ} \mathrm{C}$ in a fully humidified atmosphere of $5 \%$ $\mathrm{CO}_{2}$ in air. When the outgrowth became confluent, the cells were harvested using $0.05 \%$ trypsin (or $0.2 \%$ trypsin in cases of difficulty during cell dissociation for short time), and subcultured beyond 50 passages during a period of 39 months.

\section{Growth curve and doubling time}

Logarithmically growing cell cultures were trypsinized, and $4 \times 10^{5}$ cells were plated in $35 \mathrm{~mm}$-diameter dishes (A/S Nunc, Roskilde, Denmark) and cultured in DMEM supplemented with 10\% FBS. Cells were counted in two dishes with a hemocytometer on alternate days. The growth curve was obtained by plotting the numbers of counted cells against incubation time. The doubling time was calculated from the logarithmically growing phase of the growth curve.

\section{Chromosomal analysis}

Colchicine $(1 \mu \mathrm{g} / \mathrm{ml})$ was added to logarithmically growing cell cultures (passage 5), followed by an incubation for $1 \mathrm{~h}$ at $37^{\circ} \mathrm{C}$. The cells were harvested with trypsin and incubated for $8 \mathrm{~min}$ at $37^{\circ} \mathrm{C}$ in a hypotonic solution containing $0.075 \mathrm{M} \mathrm{KCl}$. After centrifugation, the pellet was fixed by three changes of fresh methanol : glacial acetic acid $(3: 1, \mathrm{v} / \mathrm{v})$. The fixed cells were placed on slides and air dried. Chromosome spreads were stained with Giemsa and 100 spreads were analyzed for the detection of chromosomal aberrations. 


\section{Tumorigenicity}

Three five-week-old female BALB/c nu/nu nude mice were used as recipients for tumor cell injections. Cell cultures were trypsinized and washed 3 times in DMEM with $10 \% \mathrm{FBS}$, and each $5 \times 10^{6}$ cells suspended in $0.5 \mathrm{ml}$ DMEM with $10 \%$ FBS were injected subcutaneously into the backs of these mice. During observation of tumorigenicity, one mouse died after 2 months and the remaining two mice survived another month. Autopsy was performed on all mice to study the primary tumor at the site of injection and to confirm the metastases. The removed tumor was utilized for histologic and electron microscopic studies and for further transplantation to a nude mouse.

\section{Histologic examination}

The removed tumor was fixed in isotonic-buffered formalin $(10 \%, \mathrm{v} / \mathrm{v})$, paraffin embedded, sectioned $3 \mu \mathrm{m}$ thick and stained with hematoxylin and eosin (HE staining), and subjected to microscopic examination (DIAPHOTO; Nikon, Tokyo). Cells in a culture flask were photographed directly without staining using a phasecontrast microscope (DIAPHOTO-TMD; Nikon, Tokyo).

\section{Electron microscopic study}

Tumors removed from nude mice were fixed with $2.5 \%$ glutaraldehyde in 0.1

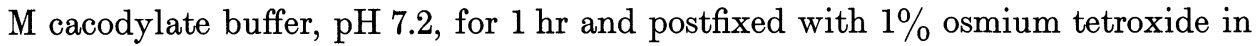
the same buffer for $2 \mathrm{hr}$. After fixation the specimen was dehydrated and embedded in Epon-Araldite. Thin sections were stained with uranyl acetate and lead hydroxide, and subjected to electron microscopic examination (H-600; Hitachi, Tokyo).

\section{Assay of the resistance to anti-cancer drugs}

The sensitivity of the TK-SA cell line to anti-cancer drugs was studied with MTT dye (3-(4, 5-dimethylthiazol-2-yl)-2, 5-diphenyl tetrazolium bromide (MTT)) reduction assay (Mosmann 1983). TK-SA cells $\left(1 \times 10^{3} /\right.$ well) were plated in a 96-well plate and cultured at $37^{\circ} \mathrm{C}$ in a humidified $5 \% \mathrm{CO}_{2}$-air mixture with 6 anticancer drugs (CDDP, VDS, ADR, CPM, UFT, Mitomycin C (MMC)) in 5 serial ten-fold diluted concentrations (each basic concentration; CDDP: $10 \mu \mathrm{g} / \mathrm{ml}$, VDS: $4 \mu \mathrm{g} / \mathrm{ml}$, ADR: $0.8 \mu \mathrm{g} / \mathrm{ml}$, CPM: $1 \mu \mathrm{g} / \mathrm{ml}$, UFT: $10 \mu \mathrm{g} / \mathrm{ml}$, MMC: $1 \mu \mathrm{g} /$ $\mathrm{ml}$ ) for 4 days (Hongo et al. 1987). Forty micrograms (20 $\mu \mathrm{l}$ of $2 \mathrm{mg} / \mathrm{ml}$ in PBS) MTT dye was added to each well, incubated under the same conditions for a further $4 \mathrm{hr}$ and the nonreacting dye and medium were removed. One and fifty microliters of dimethyl sulfoxide (DMSO) was added to each well to solubilize the MTT formazan. After complete solubilization of the MTT dye, the absorbances of each well were measured at a wavelength of $550 \mathrm{~nm}$ with 2 wavelength scanning multiwell spectrophotometer (EAR400, SLT-Labinstruments, Salzburg, Austria). 


\section{Assay of tumor markers}

CEA and CA19-9 in conditioned medium of the $5 \times 10^{5}$ TK-SA cells after 2 , $4,6,8,10$ and 12 days of incubation were examined by radioimmunoassay $\left({ }^{125} \mathrm{I}\right)$ (Thomson et al. 1969; Del Villano et al. 1983), because the serum CEA and CA199 levels of the patient were elevated. Concentration of NSE (neuron specific enolase) and TPA (tissue polypeptide antigen) were also measured by the same method.

\section{RESULTS}

An adenocarcinoma cell line was established from the pleural effusions and designated as TK-SA. The cells formed tightly packed colonies of a monolayer sheet (Fig. 1), which detached from each other with some difficulty after trypsinization. The cells had been continuously propagated for a period of 39 months (over 50 passages), and the morphology remained unchanged from passage 1 .

The $4 \times 10^{5}$ cells plated in $35 \mathrm{~mm}$ diameter dishes initially showed a decrease in cell count during the first 2 days and then the cell count increased slowly, reaching a maximum on the 18th day of incubation. The population-doubling time was estimated as $100.4 \mathrm{~h}$ from the logarithmic phase of the growth curve in Fig. 2.

Chromosome counts showed that the TK-SA cell line contained a modal chromosome number of 68 per cell, ranging from 56 to 79 in number (Fig. 3).

All the three xenografted TK-SA cells produced a visible tumor 2 weeks after subcutaneous injection into nude mice. The tumors reached a diameter of 1-2 cm after 2 months and serial transplantation was possible. Metastasis was not

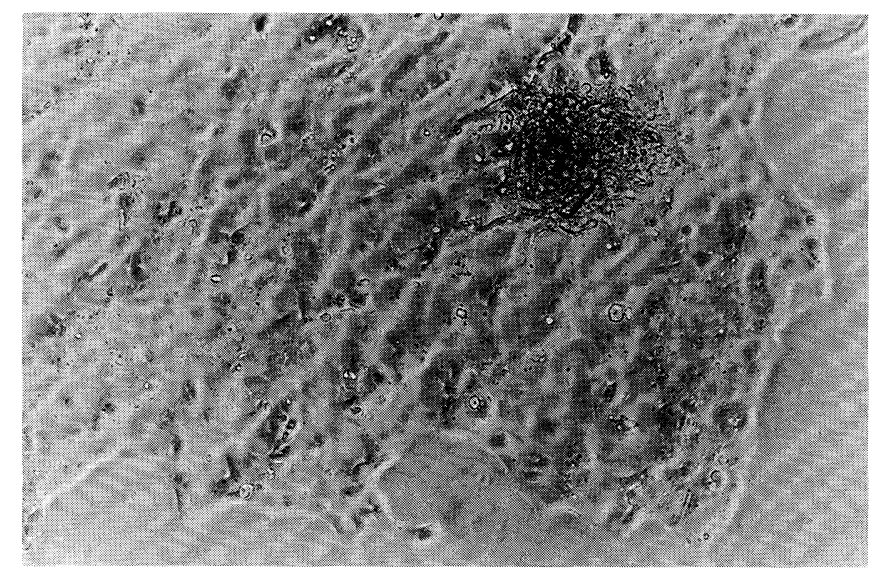

Fig. 1. A culture of TK-SA tumor cells. They formed tightly packed monolayered colonies. In some areas they were arranged in 2-3 layers. They showed no prominent cytoplasmic projections (Phasecontrast microscopy, original magnification; $\times 20$ ). 


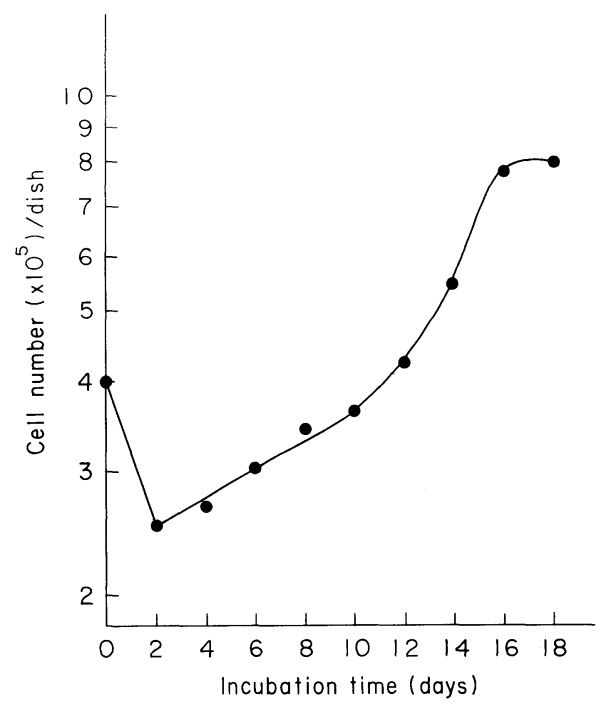

Fig. 2. Growth curve of the cell line TK-SA at passage 35. Each point represents the mean of cell counts from two dishes. The population doubling time was $100.4 \mathrm{hr}$.

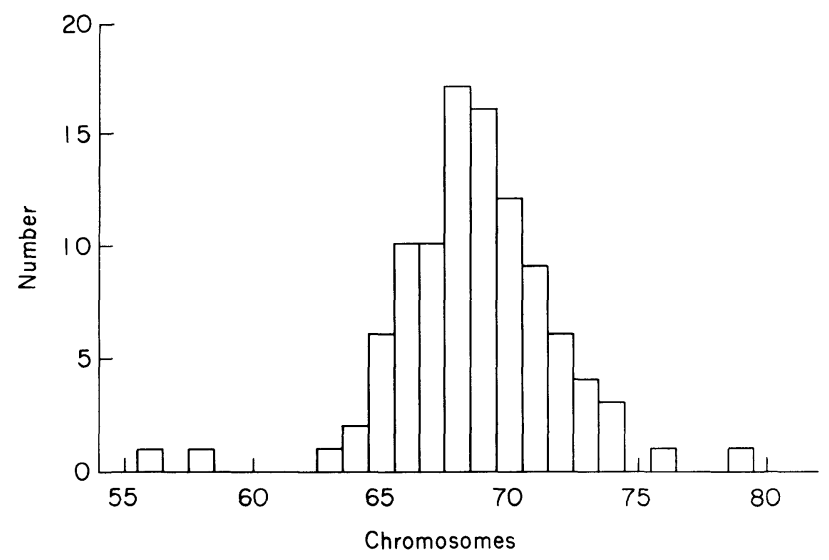

Fig. 3. Chromosomal histograms showing the spread and relative frequency of chromosome numbers in the cell line at passage 5 . The chromosome number ranged from 56 to 79 , with a mode of 68 .

observed at autopsy.

The histopathological picture showed that the polymorphic tumor cells had a moderate amount of cytoplasm with a relatively high nucleo-cytoplasmic ratio, atypical nuclei of various sizes and prominent nucleoli, indicating lung cancer. Cells formed a solid tumor with a few glandular arrangements and some necrotic foci, justifying a diagnosis of poorly differentiated adenocarcinoma (Fig. 4).

Ultrastructurally, the cell line had well-developed endoplasmic reticulum, 


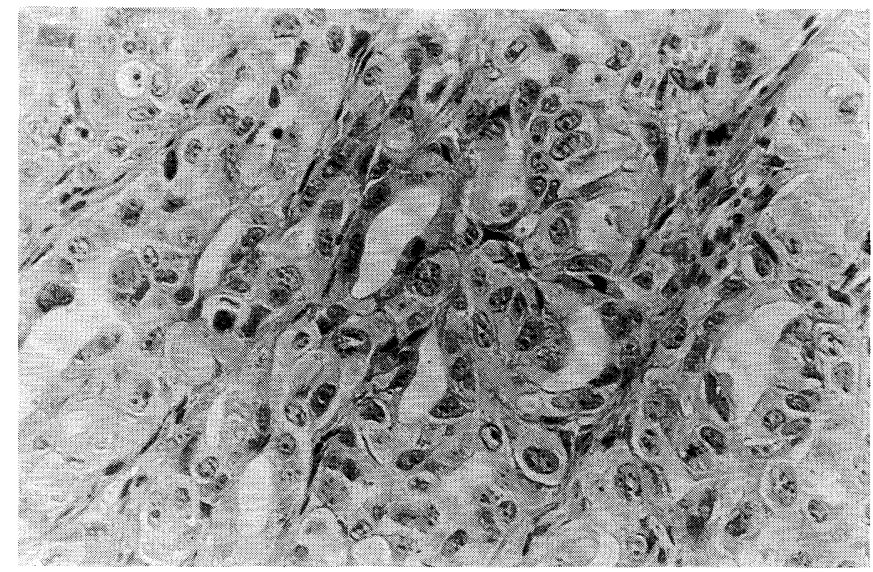

Fig. 4. Histological section of the tumor removed from nude mouse (hematoxylineosin staining). Note the polymorphic tumor cells with hyperchromatic mostly large nuclei and prominent nucleoli (microscopy, original magnification; $\times 200$ ).

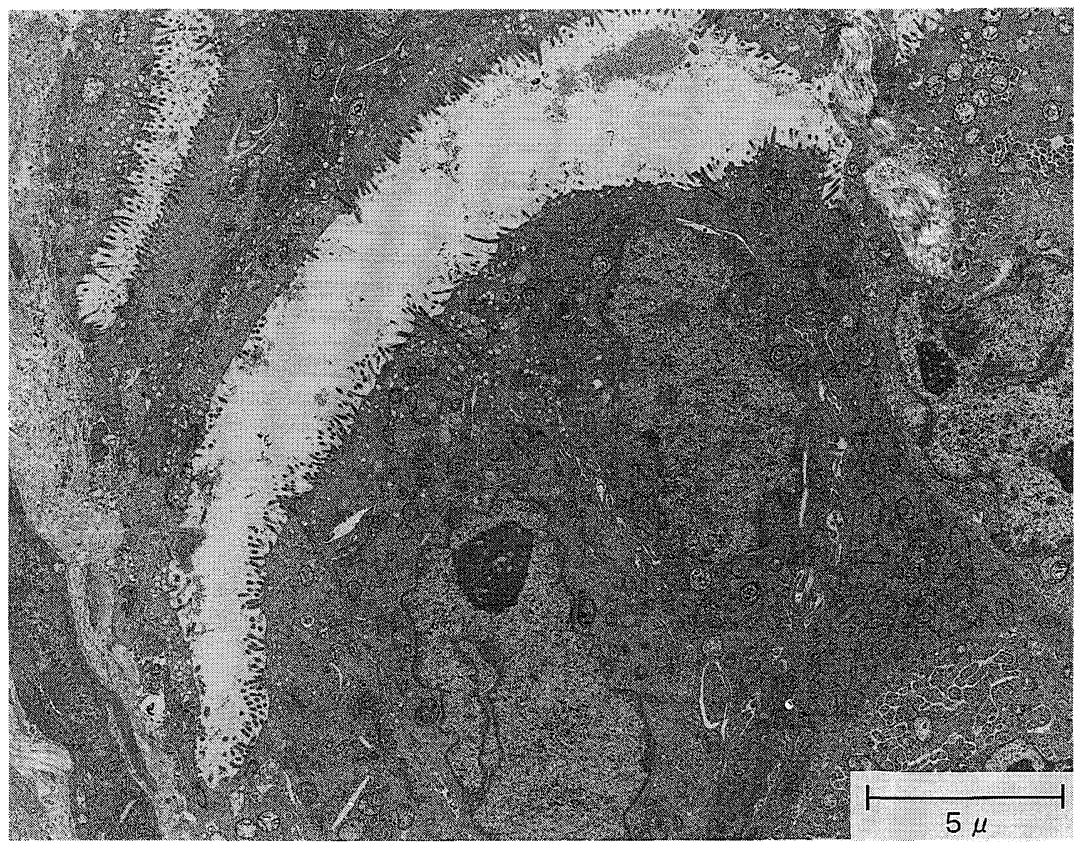

Fig. 5. Electron micrograph of TK-SA cell. Note the well-developed endoplasmic reticulums, the large Golgi apparatus, numerous mitochondria and extracellular lumina with microvilli. 


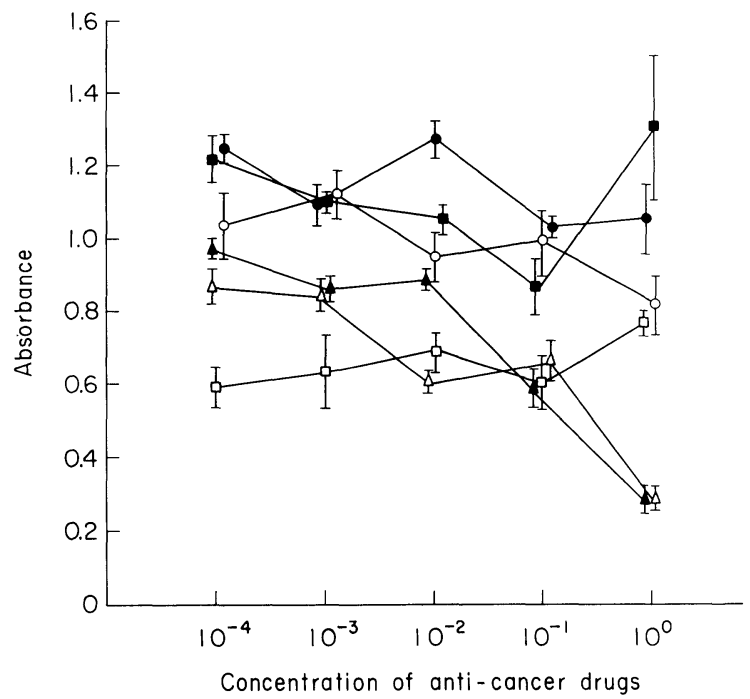

Fig. 6. Dose-response curves using TK-SA cells following continuous exposure to $\operatorname{CDDP}(\bigcirc)$, VDS $(\square), \operatorname{ADR}(\triangle), \operatorname{CPM}(\bullet)$, UFT $(\bullet)$ and $\operatorname{MMC}(\bullet)$, using the MTT dye assay. Basic concentrations of anticancer drugs were followings; $\mathrm{CDDP}, 10 \mu \mathrm{g} / \mathrm{ml}$; VDS, $4 \mu \mathrm{g} / \mathrm{ml}$; ADR, $0.8 \mu \mathrm{g} / \mathrm{ml}$; CPM, $1 \mu \mathrm{g} / \mathrm{ml}$; UFT, 10 $\mu \mathrm{g} / \mathrm{ml}$; MMC, $1 \mu \mathrm{g} / \mathrm{ml}$. The absorbance of CPM and that of UFT were nearly 1.0 and VDS, 0.7, and those of the other drugs (CDDP, ADR and MMC) were all inversely proportional to their concentration.

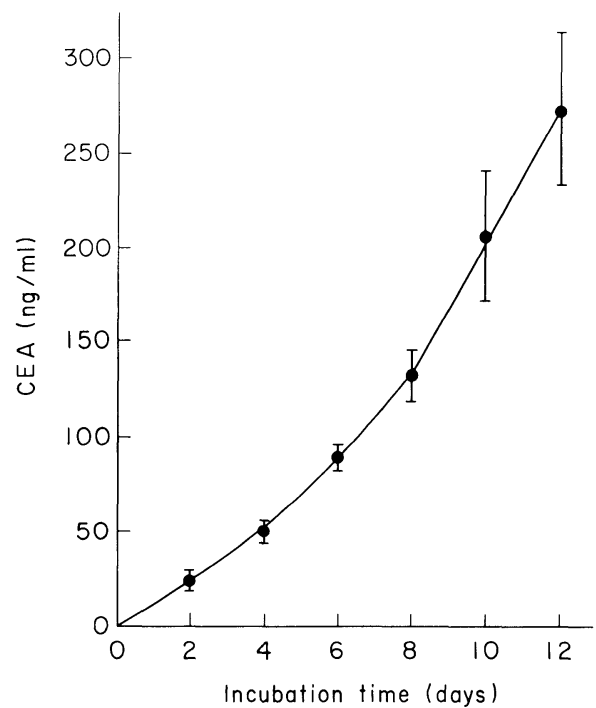

Fig. 7. CEA level in conditioned medium of TK-SA cells showing sustained increase in direct proportion to the incubation time. 


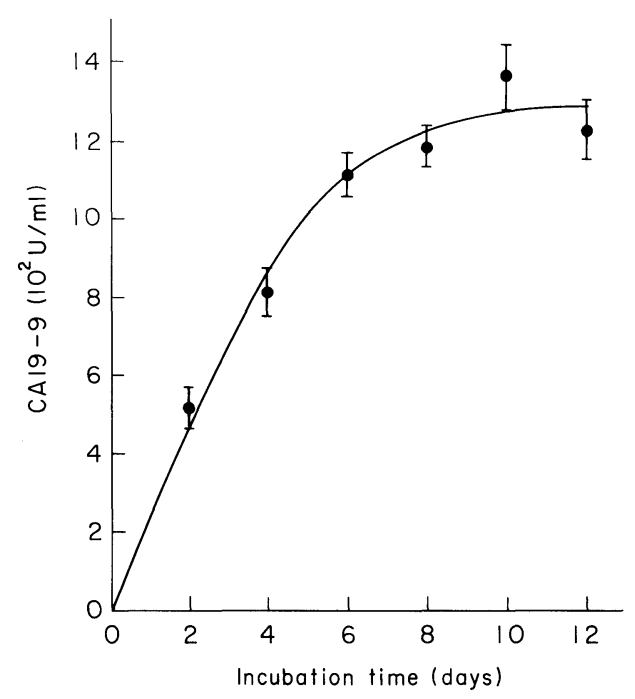

Fig. 8. CA19-9 level in conditioned medium of TK-SA cells showing an increase and subsequent plateau formation after 10 days of incubation.

large Golgi apparatus, numerous mitochondria, poorly developed desmosomes, and extracellular alveoli with microvilli, confirming the characteristics of adenocarcinoma (Fig. 5).

The MTT assay showed that the absorbances of CPM and UFT were both near 1.0 and that of VDS was 0.7 , regardless of the concentration of the anti-cancer drugs. The absorbances of CDDP, ADR and MMC decreased inversely related to the concentration of the drugs (Fig. 6).

The concentration of CEA in the conditioned medium of the TK-SA cell line increased in proportion to the incubation time (Fig. 7). The concentration of CA19-9 showed an initial increase a bearing direct relation to incubation time but reached a plateau after 10 days of incubation (Fig. 8). Neither NSE nor TPA was detected in the conditioned medium before and after the incubation (data not shown).

\section{Discussion}

In establishing a lung cancer cell line from pleural effusions, most investigators use Ficoll to separate other cells. On the contrary, we used unseparated pleural effusions on the presumption that the presence of growth factors and other feeder cells, e.g., blood cells within the samples, may have a positive impact on the growth of tumor cells. We used a 96-well plate because it makes TK-SA cells produce higher level of autocrine factors per unit volume than big well, so that the cells might survive even under the unstable condition after the sudden change from in vivo to in vitro.

The TK-SA cell line, established from the pleural effusions, was substrate- 
adherent in terms of growth characteristics, and showed a long population doubling time $(100.4 \mathrm{hr})$. This pattern of slow growth was unexpected in view of the downhill clinical course of the patient where the malignant effusions accumulated rapidly and repeatedly and the patient died soon after pleuritis developed. Similarly, the tumor xenografted to the nude mouse showed a slow growth rate and did not metastasize, which also shows discordance with the clinical course. We speculate that we picked up one of the slower growing types among heterogeneous cancer cells within the effusion. We further speculate that we were not able to culture the rapidly growing aggressive cancer cells, which due to their active metabolism, were unable to adapt to the sudden change in environment from in vivo to in vitro.

Electron microscopic study showed that this cell line was compatible with typical adenocarcinoma with well-developed endoplasmic reticulum and Golgi apparatus, extracellular lumina with microvilli and poorly developed desmosomes (McDowell et al. 1978). However no secretory granules indicative of cellular secretion were observed, although the cell line was secreting CEA and CA19-9.

The patient died although she was treated with anti-cancer drugs (CDDP, VDS, ADR, CPM and UFT). We investigated the sensitivity and resistance of the TK-SA cells to these drugs and MMC (as control) using MTT dye assay. As expected, this cell line was resistant to CPM and UFT, and sensitive to MMC. Although ADR did not seem to be effective clinically, no resistance was demonstrated in cell cultures.

CEA is an $180 \mathrm{kD}$ embryonic protein used as a tumor marker for almost all cancers, including lung cancer (Gefro et al. 1971). CA19-9 is a $36 \mathrm{kD}$ sialylated $\mathrm{Le}^{\mathrm{a}}$-active pentasaccharide with a carbohydrate antigenic determinant (Koprowski et al. 1979; Magnani et al. 1981, 1982), and used as a tumor marker of pancreatic cancer, biliary cancer, etc. (Koprowski et al. 1981; Herlyn et al. 1982). Our study showed that the TK-SA cell line produced both CEA and CA19-9. Although the concentration of CEA steadily increased in direct relation to incubation time, the concentration of CA19-9 reached a plateau after 10 days of incubation. In case of CA19-9, a negative feed-back system may be involved in the metabolism of CA19-9.

The presently established cell line may contribute to the elucidation of mechanisms of tumor-marker production by lung cancer cells and be applied to various models of cancer research such as histogenesis, metabolism, mechanisms of autonomous growth and metastasis and resistance to anticancer drugs.

\section{Acknowledgment}

We thank Dr. Hisaaki Saeki of the Cancer Cell Repository, Institute of Development, Aging and Cancer, Tohoku University and Mr. Mitsuji Kaji of the Laboratory of Electron Microscopy, Institute of Development, Aging and Cancer, Tohoku University for their generous assistance, and Ms. Seiko Kondo for her clerical assistance in preparing the 
manuscript.

\section{References}

1) Del Villano, B.C., Brennan, S., Brock, P., Bucher, C., Liu, V., McClure, M., Rake, B., Space, S., Westrick, B., Schoemaker, H. \& Zurawski, V.R., Jr. (1983) Radioimmunometric assay for a monoclonal antibody-defined tumor marker, CA19-9. Clin. Chem., 29, 549-552.

2) Gerfo, P.L., Krupey, J. \& Hansen, H.J. (1971) Demonstration of an antigen common to several varieties of neoplasia. Assay using zirconyl phosphate gel. N. Engl. J. Med., 285, 138-141.

3) Gold, P. \& Freedman, S.O. (1965a) Demonstration of tumorspecific antigens in human colonic carcinomata by immunological tolerance and absorption techniques. J. Exp. Med., 121, 439-462.

4) Gold, P. \& Freedman, S.O. (1965b) Specific carcinoembryonic antigens of the human digestive system. J. Exp. Med., 122, 467-481.

5) Herlyn, M., Sears, H.F., Steplewski, Z. \& Koprowski, H. (1982) Monoclonal antibody detection of a circulating tumor-associated antigen. 1. Presence of antigen in sera of patients with colorectal, gastric, and pancreatic carcinoma. J. Clin. Immunol., 2, 135-140.

6) Hongo, T., Fujii, Y., Mizuno, Y., Haraguchi, S. \& Yoshida, T.O. (1987) Anticancer drug sensitivity test using the shortterm microplate culture and MTT dye reduction assay. Jpn. J. Cancer Chemother., 14, 472-478.

7) Koprowski, H., Steplewski, Z., Mitchell, K., Herlyn, M., Herlyn, D. \& Fuhrer, P. (1979) Colorectal carcinoma antigens detected by hybridoma antibodies. Somatic Cell Genet., 5, 957-972.

8) Koprowski, H., Herlyn, M., Steplewski, Z. \& Sears, H.F. (1981) Specific antigen in serum of patients with colon carcinoma. Science, 212, 53-55.

9) Magnani, J.L., Brockhaus, M., Smith, D.F., Ginsburg, V., Blaszczyk, M., Mitchell, K.F., Steplewski, Z. \& Koprowski, H. (1981) A monosialoganglioside is a monoclonal antibody-defined antigen of colon carcinoma. Science, 212, 55-56.

10) Magnani, J.L., Nilsson, B., Brockhaus, M., Zopf, D., Steplewski, Z., Koprowski, H. \& Ginsburg, V. (1982) A monoclonal antibody-defined antigen associated with gastrointestinal cancer is a ganglioside containing sialylated lacto-N-fucopentaose II. $J$. Biol. Chem., 257, 14365-14369.

11) Masuda, N., Fukuoka, M., Takada, M., Kudoh, S. \& Kusunoki, Y. (1991) Establishment and characterization of 20 human non-small cell lung cancer cell lines in a serum-free defined medium (ACL-4). Chest, 100, 429-438.

12) McDowell, E.M., McLaughlin, J.S., Merenyl, D.K., Kieffer, R.F., Harris, C.C. \& Trump, B.F. (1978) The respiratory epithelium. V. Histogenesis of lung carcinomas in the human. J. Natl. Cancer Inst., 61, 587-606.

13) Mosmann, T. (1983) Rapid colorimetric assay for cellular growth and survival: Application to proliferation and cytotoxicity assays. J. Immunol. Methods, 65, 5563.

14) Thomson, D.M.P., Krupey, J., Freedman, S.O. \& Gold, P. (1969) The radioimmunoassay of circulating carcinoembryonic antigen of the human digestive system. Proc. Natl. Acad. Sci., 64, 161-167.

15) Tominaga, S., Hirose, K. \& Kuroishi, T. (1989) Future prediction of cancer deaths in Japan. Jpn. J. Cancer Chemother., 16, 101-111. 